\title{
Geological Lineament Extraction Using Landsat 8 (OLI) in Parts of Osun State, Southwestern Nigeria
}

\author{
Christopher Oche Albert ${ }^{1}$, Alaga Abayomi Taofeek ${ }^{2}$ \\ ${ }^{1,2}$ COPINE, Advanced Space Technology Application Laboratory (ASTAL), National Space Research and Development Agency \\ (NASRDA), P.M.B 022, Obafemi Awolowo University, Ile-Ife, Osun State, Nigeria
}

\begin{abstract}
Geological lineaments are essentially straight or curve lines on the earth surface that gives information about the subsurface structures. Economic mineral resources accumulation, fracture zones for groundwater, engineering (slope stability, foundation study, sites selection in the construction of dams, roads, bridges, etc), earthquakes and hazard monitoring, are related to a better understanding and interpretation of lineament. Lineament in parts of Osun State was extracted from Landsat 8 (OLI) image both manually and automatically. Comparison was done between the manually and automatically extracted lineaments which led to further analysis to be done from the manually digitized lineaments. Lineament interpreted was verified from geological map and with known structural features of the study area. Result from evaluation of Lineament indicates a NNE-SSW as the major structural trend. Also the deformation characteristics of the rocks types were known based on the density, intersection and length of lineament of the study area.
\end{abstract}

Keywords: Geological Lineaments, Subsurface Structures, Landsat 8 (OLI), Geological Map, NNE-SSW

\section{Introduction}

Lineaments are significant lines of landscapes which reveal the hidden architecture of the rock basement. Lineament is essentially rectilinear features resulting from fracturing/faulting or structurally controlled topographic lines. They are in fact the character lines of the earth's "physiognomy" (1). The subsurface effect is valid if the origin of the lineament is controlled by geological structures such as faults and fractures. Other types of lineaments resulted from morphological effects (stream channels or drainage divides) or human effects (roads, field boundaries) can also exist in regions (2). Most lineaments are identified through satellite imagery, topographic, gravimetric or magnetic data. According to Pena and Abdelsalam (3), the objectives of a lineament analysis is to derive information about geological structures from the length, azimuth direction, and spatial distribution of lineaments.

Manual and automated method is generally used to extract lineament from satellite image. Image processing techniques lead to visually interpreting lineament based on identification in the satellite image. After careful study of the bands characteristics, a composite of the infrared and visible bands was used for the manual extraction. The infrared bands were used for the automated extraction based on LINE option of PCI Geomatica using the Canny Algorithm which involves three steps: edge detection, thresholding and curve extraction after specifying several parameters for interpretation.

\section{Study Area}

The study area lies majorly in the Ilesha gold mining areas of Osun State, southwestern Nigeria. It consists majorly of three Local Government Areas (LGA), which is bordered by several other LGA's in Osun State. (figure 1).

Geologically, the study falls within The Ifewara area of southwestern Nigeria schist belts, which constitutes part of the Nigerian Basement Complex; a part of the African crystalline shield (figure 2). The Nigerian Basement Complex forms part of the Pan African mobile belt lying east of the West African craton (4).

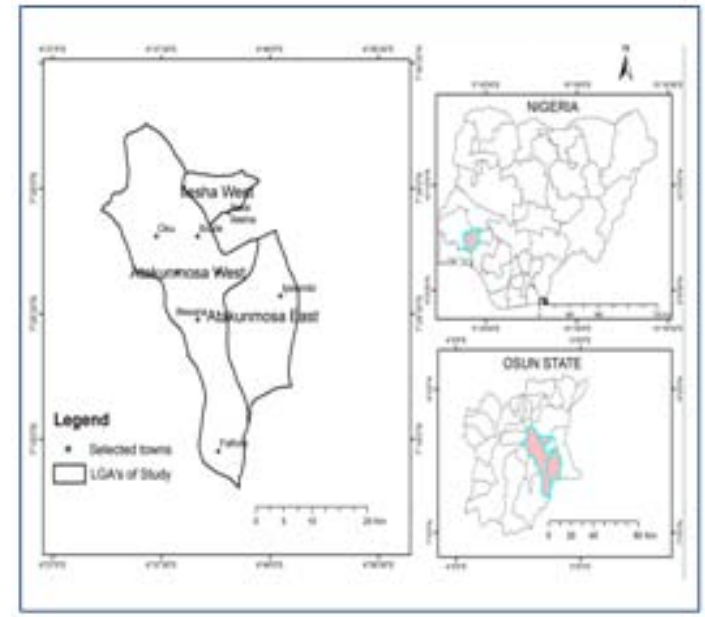

Figure 1: Map of the study area

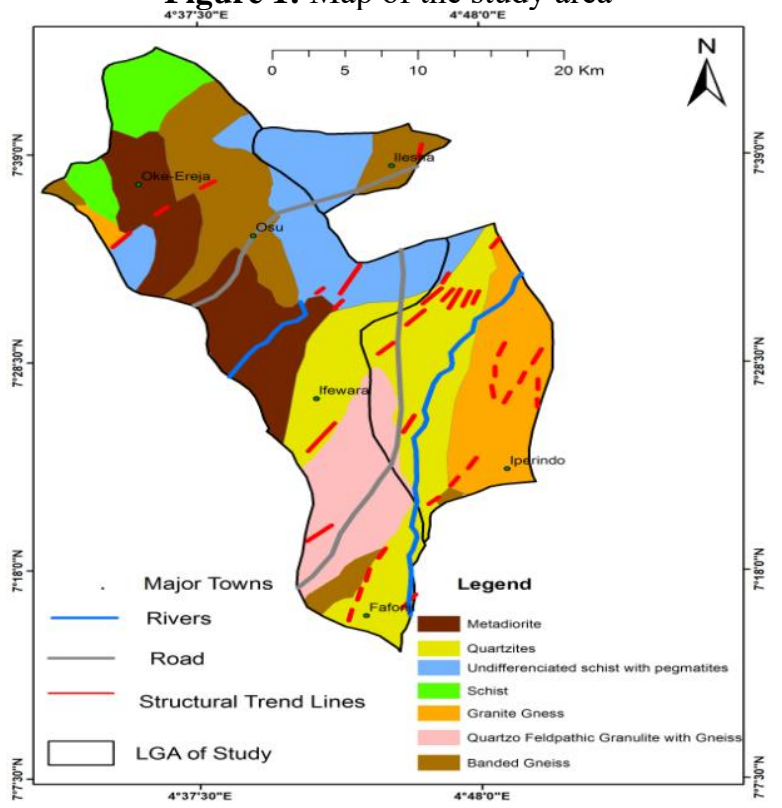

Figure 2: Geological Formations in Ilesha region 


\section{International Journal of Science and Research (IJSR) \\ ISSN (Online): 2319-7064}

Index Copernicus Value (2013): 6.14 | Impact Factor (2015): 6.391

\section{Materials and Methodology}

Landsat 8 OLI collects data in nine spectral bands with spatial resolution of 30 meters for bands 1 to 7 and 9 . The resolution for band 8 (panchromatic) is 15 meters (USGS, July 1, 2016). Landsat scene (190/055) covers the study area and the spectral differences of a variety of characteristics that is required for lineament study make it possible to use Landsat 8. Band 7 and 6 (shortwave infrared) is very important for extraction of lineament and other geological features. Band 7 image subset of the study area initially made (figure 3). The image is now process before manual digitizing of the lineament was done from the composite image.

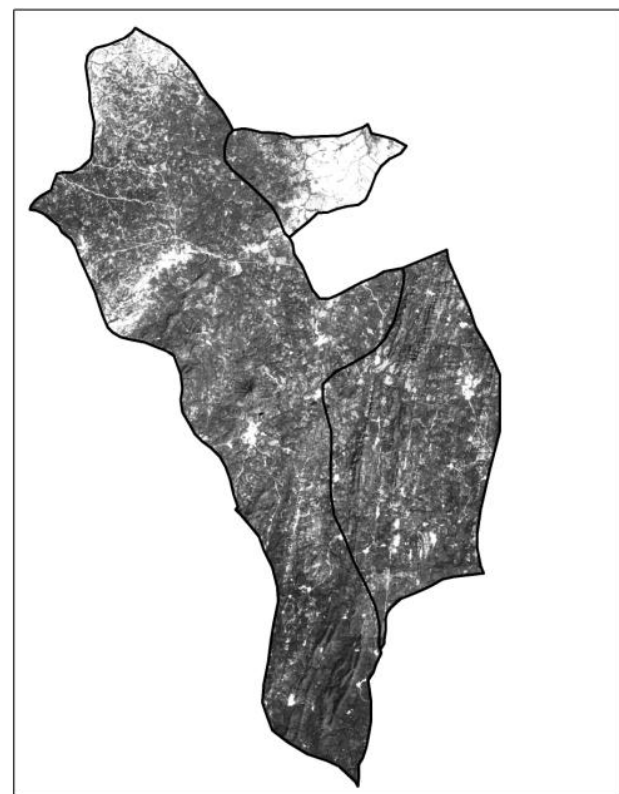

Figure 3: Band 7 image subset of the study area.

Automatic extraction was done using the LINE option of PCI Geomatica software. The canny algorithm made it possible to extract curve-linear features based on defined set of parameters from the image and records it in a vector layer for further analysis. The imput band is infrared. The extracted linear features related to geology were retained as other features like roads, straight edges and other man made boundary was removed.

\section{Results}

There is no definite way of evaluating geological lineaments; this is usually based on the purpose of the study or the author's discretion. Automatically extracted lineament was compared to the manually digitized lineament and it was realized that the automated lineament cannot properly identify faults or faults zones in the study area (figure 4). Manually extracted lineament is strongly related to the length and pattern of faults as it sufficiently interpret them. So manually extracted lineament was used for further analysis. The lineament was well distributed in the study area with the SE corner having more lineaments (figure 5).

Lineament intersection is done by counting the number of lineament intersection per unit area, Fractures zones for groundwater survey, has been defined and proven overtime to be successful based on areas of densely intersected lineament (figure 6). There are areas with abundance of faults parallel to each other, they do not intersect and the lineament intersection density is low. The areas with densely intersected lineaments are consistent with the structural trend of the study area.

Lineament density analysis calculates the frequency of lineaments per unit area. It produces map showing concentrations of the lineaments over the area (figure 7). The density map generated show lineament concentration in the NE-SW direction, with different density, which defines the prominent Ifewara Fault Zone (IFZ) in the study area. The IFZ is well described in previous study, however other relatively minor fault and faults zones can be classify from the lineament map.

Majority of lineament corresponds to generally harder rocks and not the ductile rocks. The highest percentage of lineament is in quartzites followed by granulite and granite rock. The lowest percentage of lineament is in schist and banded gneiss (figure 8). Lineaments are shorter in the quartzites rock with the dominant $\mathrm{E}-\mathrm{W}$ direction which corresponds to the trend of gold occurrence in the study area. There is a positive correlation between the lineament in quartzites and quartz feldpathic granites because their fracture pattern are similar in terms of orientation, since both rocks undergo brittle deformation but dissimilar when related to schists because of their brittle nature.

Lineament orientation is analysed by the rose diagram. Rose plot display frequency of lineament for regular intervals or orientation bin (figure 9), intervals in this study is 15 degrees. Diagram count each lineament line as an element regardless of its length. Result indicates a dominant NE-SW lineament orientation and a minor orientation in the E-W direction.

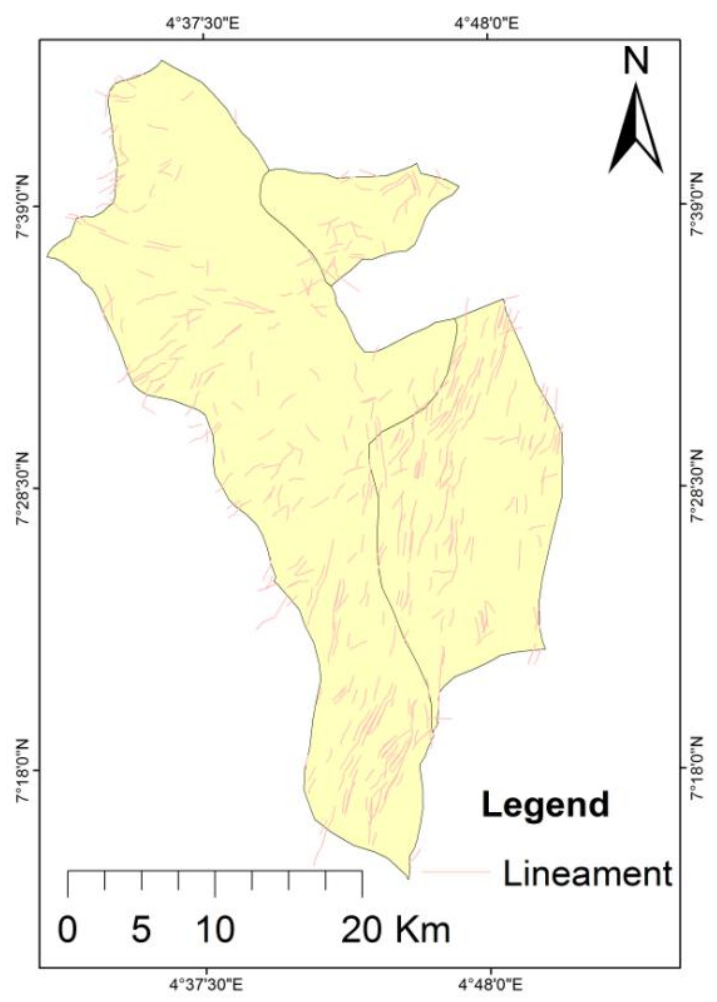

Figure 4: Automatically extracted lineaments 
International Journal of Science and Research (IJSR)

ISSN (Online): 2319-7064

Index Copernicus Value (2013): 6.14 | Impact Factor (2015): 6.391

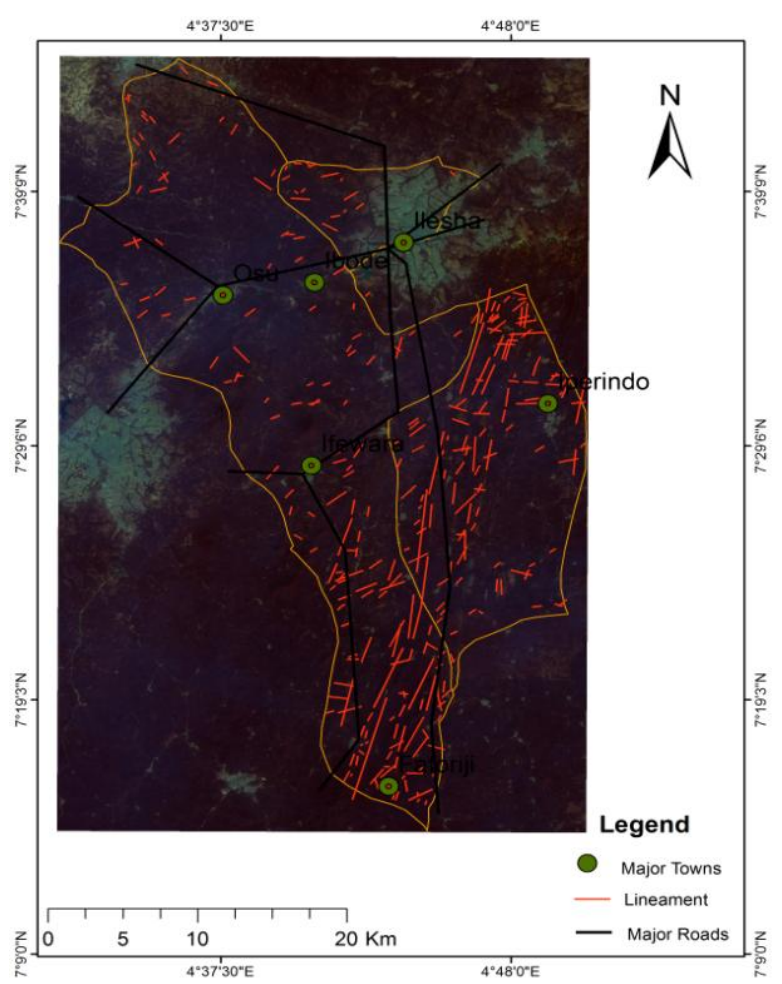

Figure 5: Manually digitized lineaments

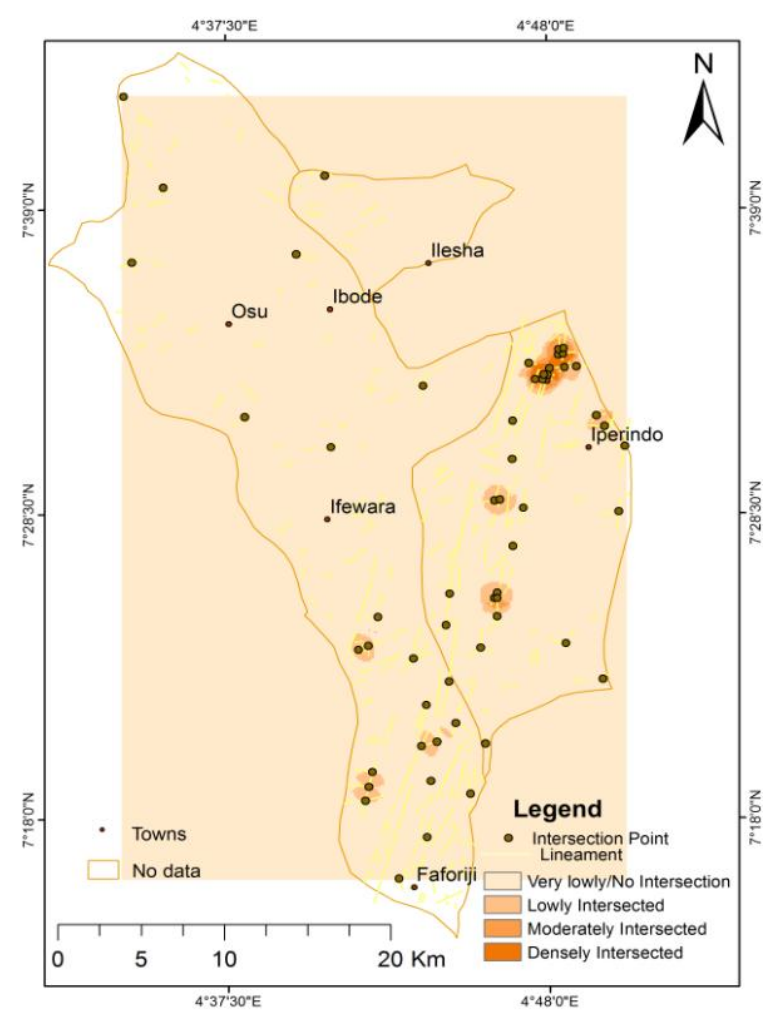

Figure 6: Lineament Intersection

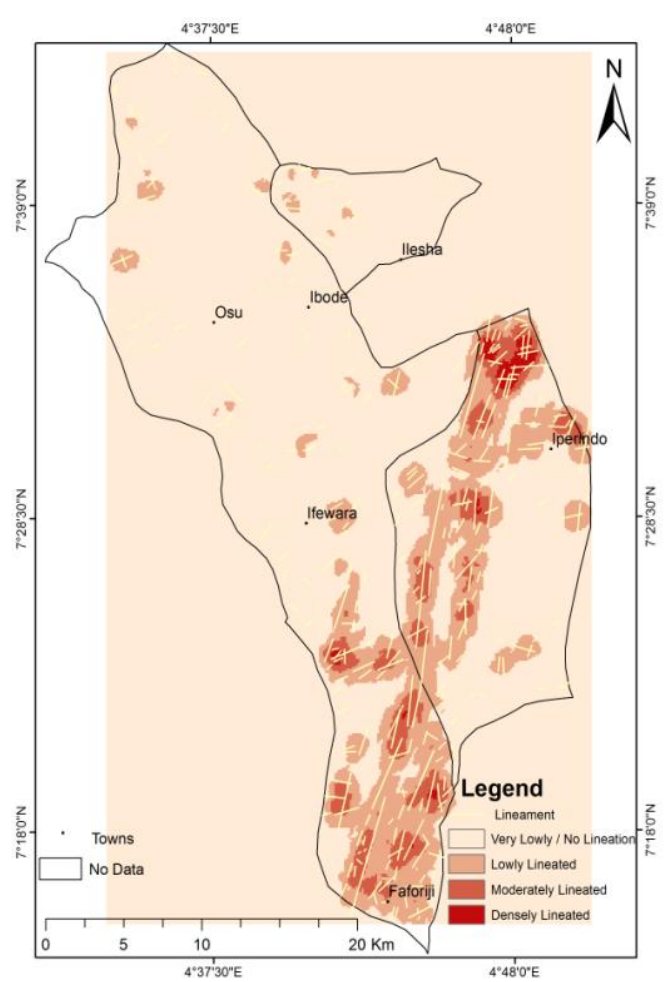

Figure 7: Lineaments density

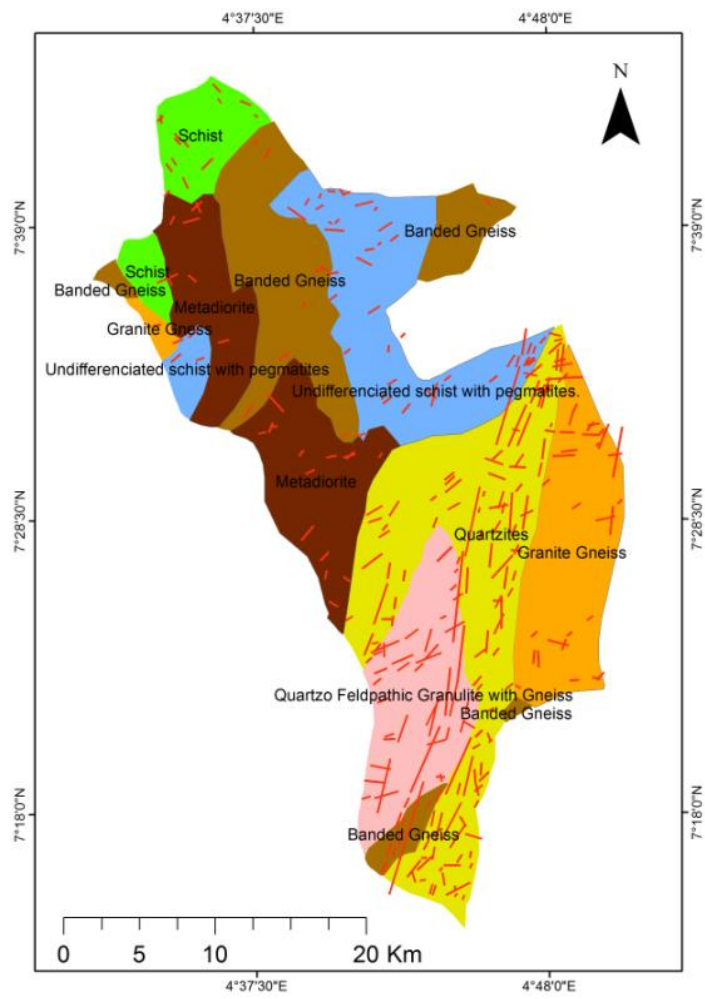

Figure 8: Overlay of geology and extracted lineaments. 


\section{International Journal of Science and Research (IJSR) \\ ISSN (Online): 2319-7064}

Index Copernicus Value (2013): 6.14 | Impact Factor (2015): 6.391

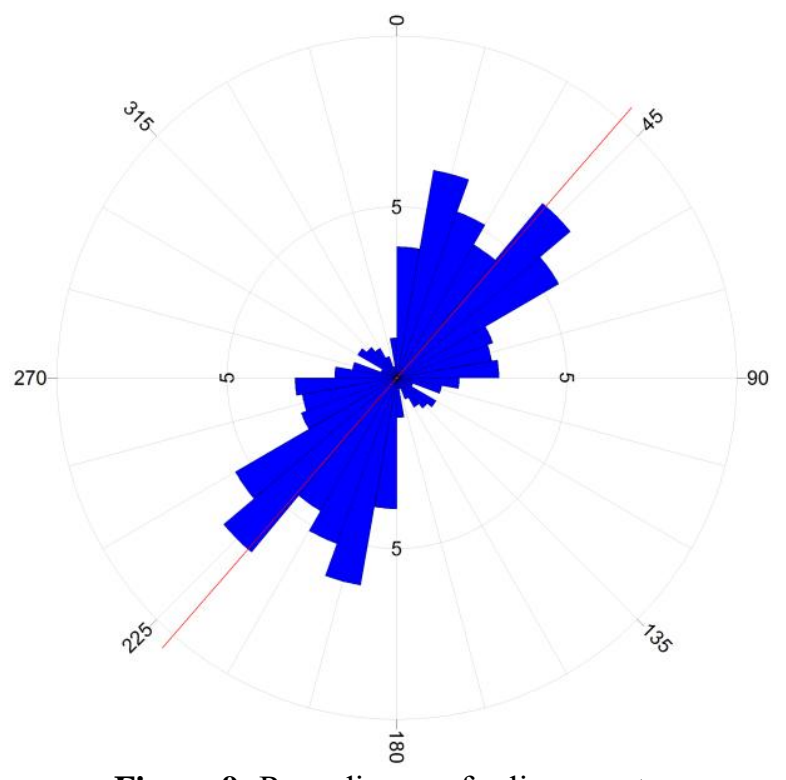

from Federal University of Technology, Minna, Nigeria. His current research interest is remote sensing geology.

Figure 9: Rose diagram for lineaments.

\section{Conclusions}

Remote sensing method can extract lineament in an inaccessible tropical rain forest. Manually extracted lineament, though subjective based on author's experience, can yield important result, especially when compared to known structural features. Results will be enhanced if geology, geophysics and topography data is added as auxiliary information.

\section{Recommendations}

Manual lineament extraction is a subjective process. Geological field study is the best way to test the accuracy of lineaments.

\section{References}

[1] Nigerian Geological Survey Agency (NGSA), "Lineaments map of Nigeria" Published by the authority of the federal republic of Nigeria, 2006

[2] G. Sarp, Lineament analysis from satellite images, northwest of Ankara. MSc thesis submitted to the Graduate school of natural and applied sciences, Middle Eastern technical university, 2005.

[3] S. A. Pena, and M. G. Abdelsalam, orbital remote sensing for geological mapping in southern Tunisia: Implication for oil and gas exploration: Journal of African Earth Sciences, vol. 44, no. 2, p. 203-219, 2006.

[4] M.A. Rahaman, Recent advances in the study of the basement complex of Nigeria. In: P.O. Oluyide (Ed.), Precambrian Geology of Nigeria. Geological Survey of Nigeria, pp. 11-43.1988.

\section{Author Profile}

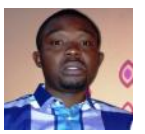

Christopher, Oche Albert is presently working as a scientific officer with NASRDA; the Nigeria space agency, where he applied space technology as a key driver for socio-economic development. He previously obtained MSc degree in Petroleum Geology from the University of Malaya, Kuala Lumpur, Malaysia and a B.Tech (Geology) degree 